\title{
A conceptual contribution to battles in the brain
}

\author{
Harry Smit
}

Received: 3 February 2009/Accepted: 11 January 2010/Published online: 21 January 2010

(C) The Author(s) 2010. This article is published with open access at Springerlink.com

\begin{abstract}
Badcock and Crespi have advanced the hypothesis that autism and schizophrenia are caused by imbalanced imprinting in the brain. They argue that an imbalance between the effects of paternally and maternally expressed genes on brain development results in either an extreme paternal (autism) or maternal brain (schizophrenia). In this paper their conceptual model is discussed and criticized since it presupposes an incoherent distinction between observable physical and hidden mental phenomena. An alternative model is discussed that may be more fruitful for investigating the possible role of imprinted genes in the development of social behaviour. The development of crying and reactive crying and behaviours necessary for collaborative action are discussed as a promising research area for understanding the effects of imprinted genes.
\end{abstract}

Keywords Genomic imprinting - Kinship theory - Theory of mind . Autism - Schizophrenia

\section{Introduction}

Genomic imprinting is the phenomenon that the expression of an allele in the current generation depends on whether the allele was present in a sperm or egg during the previous generation. It was discovered about 20 years ago and has since then been a major research topic. At first it was studied within the fields of molecular and evolutionary biology; nowadays it is studied within the fields of neuroscience and psychology as well since imprinted genes are involved in brain development (for a review, see Wilkinson et al. 2007). Studies have shown

H. Smit (ه)

Department of Cognitive Neuroscience, Faculty of Psychology and Neuroscience, Maastricht University, P.O. Box 616, 6200 MD Maastricht, The Netherlands

e-mail: h.smit@maastrichtuniversity.nl 
that paternally and maternally expressed genes contribute differently to brain development.

Badcock and Crespi (2006, 2008) have advanced the hypothesis that autism and schizophrenia are caused by imbalanced genomic imprinting in the brain. They hypothesize that paternally expressed genes favour the development of what they call mechanistic cognition, while maternally expressed genes favour the development of mentalistic cognition. Perturbations in neural pathways modulated by the products of imprinted genes, cause according to Badcock and Crespi autism or schizophrenia. Badcock and Crespi have assembled a massive amount of data to underpin their hypothesis. Yet interesting as their papers are, their hypothesis remains elusive, since the data they have discussed do not confirm nor disconfirm their ideas. One problem is that there is a lack of clear data about the role of imprinted genes in brain development. Another problem is that their model may be elusive because of conceptual incoherence.

Concepts determine what makes sense and therefore delineate the logical space within which facts are located. If concepts are misused or used nonsensically, then this will introduce conceptual incoherence in a conceptual framework. Hypotheses developed within the confines of an incoherent framework may not be hypotheses at all that can be tested in experiments. In this paper I will discuss the conceptual model developed by Badcock and Crespi and argue that their model suffers incoherence. I will discuss an alternative conceptual model that is more interesting for framing hypotheses about autism and schizophrenia (and about the possible role of imprinted genes in their aetiology). Discussing conceptual problems will, I hope, provide a clearer picture of what interesting problems are worth pursuing in future theoretical and empirical studies.

\section{Understanding other minds}

I take as a starting point for my discussion the conceptual framework developed by Badcock in a book chapter titled: 'Mentalism and mechanism; the twin modes of human cognition'. In this paper Badcock (2003) discusses the difficulties ethologists, behaviorists, and evolutionary biologists had with the 'mental domain'. These scientists made a distinction between the observable, physical domain and unobservable, mental domain and doubted whether a scientific approach to the mental domain is possible. For example the evolutionary biologist George Williams 'had no inclination to deny the mental realm', yet was 'inclined to delete it from biological explanation, because it is an entirely private phenomenon, and biology must deal with the publicly demonstrable' (Williams 1992, p. 4). According to Badcock most ethologists, behaviorists and evolutionary biologists disregarded the mental domain for the methodological reasons discussed by Williams.

The tide turned according to Badcock after the 'discovery' of — what Premack and Woodruff (1978) have called — a theory of mind (ToM), i.e. the ability to apply mental predicates to humans and other animals. The presence of ToM in humans and other 'higher' animals shows according to Badcock that ToM is the product of evolution. ToM has according to him been selected since ToM enables creatures to 
make predictions about the mental states of others. Hence Williams' problem, that mental phenomena are not publicly observable, has apparently already been 'solved' during the course of evolution, for animals possess a selected ability (i.e. a ToM) that enables them to understand (and to construct predictions about) the mental states of con-specifics (and the mental states of members of other species). Consequently, if the theory of mind evolved as a separate module in the brain/mind, then the problem arises which brain and cognitive structures or processes enable 'higher' animals to develop a ToM. The 'discovery' of ToM is for that reason used by Badcock to explore new avenues of research into the mind.

Badcock distinguishes two modes of cognition (corresponding to two forms of behaviour and two modules in the brain). He makes a conceptual distinction between 'mechanistic cognition', i.e. interpreting and explaining the world in terms of (simple) mechanical models without using mental concepts, and 'mentalistic cognition', i.e. explaining and understanding the inner life of others with the help of an acquired theory of mind. The way an individual acquires a ToM is understandable in terms of ontogenetic and phylogenetic processes. ToM is acquired through maturation of the brain and learning, and the capacity to use a ToM has been 'acquired' by the human species through variation and selection processes. Whether children possess a ToM is determined through studying their ability to solve so-called false-belief tasks (such as the well-known Sally and Anntask). Since 3-4 year-old children are able to solve such a task, developmental psychologists have argued that children at this age have developed a ToM. Interestingly, children with autism appear to lack a theory of mind (or, to be more precise, the development of a ToM is in children with autism retarded). Hence these children have problems with 'interpreting' other's intentions, beliefs and emotions. This explains according to Badcock why they fail to understand social-emotional behaviour depending on 'mentalistic cognition' and are hardly able to enter socialemotional interactions. If one explains autism in terms of the opposition between 'mechanistic and mentalistic cognition', then children with autism perceive the social world as if they are behaviorists or ethologists since they possess only the 'mechanistic mode of cognition'. Badcock quotes Baron-Cohen (1995) to illustrate this idea: 'Lacking a theory of mind is in one sense akin to viewing the world as a behaviorist'. Interestingly, this opposition between 'mechanistic and mentalistic cognition' has been advanced by individuals with autism too. Temple Grandin is a well-known example. She has stated that, as an autistic person, she lacks the 'mentalistic mode of cognition' which is according to her characteristic for the human species. Based on ideas of MacLean (his well-known yet contentious ideas about the evolution of the tripartite human brain), Grandin has advanced the hypothesis that the part of the brain that is responsible for 'mentalistic cognition' has recently been 'added' to the phylogenetically older, animal brain (Grandin and Johnson 2005). Since the development of this newly 'added' part is disturbed in autism, children with autism 'revert' to the older 'animal brain' responsible for 'mechanistic cognition'. She assumes that children with autism use this part of the brain more intensively than normal people and this explains according to her why children with autism develop 'mechanistic cognition' better. This illuminates according to Grandin why some children with autism have exceptional skills. 
Badcock and Crespi (2006, p. 1020) conclude that 'autism thus involves loss of several uniquely human features mediated by the neocortex, such as language, cognitive capacity and complex social interaction (...), but it often also entails concomitant gains in mechanistic and perceptual skills that Grandin describes as characteristic of hyper-specialized animal cognition'.

\section{A paternal and maternal brain}

Research on mono- and dizygotic twins and on the inheritance of autism and schizophrenia in families has shown that these disorders have, in part, a genetic cause. Subsequent research into possible genetic causes has shown that these disorders are associated with single nucleotide-variations; so-called copy number variations (segments of DNA ranging from 1 kilobase to several megabases which are also described as small chromosomal mutations like deletions, duplications, and translocations); disturbed expression of imprinted genes; and disruptions of epigenetic inheritance. It is an objective of molecular neuroscience to unravel the effects of these genetic variations on brain development.

It is probable that disrupted expression of imprinted genes is involved in the aetiology of some cases of autism and schizophrenia. Yet there is no evidence that imprinted genes are involved in most cases. Badcock and Crespi have advanced the bold hypothesis that most cases are caused by mutations that disturb developmental pathways modulated by imprinted genes. Hence they assume that imprinted genes are the key to understanding of what goes wrong in autism and schizophrenia. They use an evolutionary perspective, i.e. the kinship theory of genomic imprinting, to explain why humans are vulnerable to disruptions in these pathways. Kinship theory can according to them help us to understand why mutations, causing perturbations in pathways modulated by imprinted genes expressed in the brain, result in two related yet opposing forms of psychopathology. The 'hypomentalistic brain', typical for autism, is according to them caused by disrupted development resulting in a shift towards the 'mechanistic brain', while 'hypermentalistic' cognition, typical for schizophrenia, is caused by a shift towards the 'mentalistic brain'. Schizophrenia is according to them the prototypical example of the 'hypermentalistic' disorder, since individuals with schizophrenia have delusions and hallucinations (which cannot, according to their definitions, be perceived with a 'mechanical brain'). This raises the question as to why disruptions in pathways modulated by imprinted genes cause two sister-disorders. The answer is according to Badcock and Crespi that mutations cause a disturbed balance between what they call the paternal and maternal brain culminating in either a 'hypo-' or a 'hypermentalistic' brain. Based on experiments done (and ideas developed) by Keverne c.s. they have argued that there is a tug of war going on in the brain between paternally and maternally expressed genes. The evolution of this genetic conflict is according to them understandable if the shift in the regulation of maternal behaviour is taken into consideration that has occurred during the evolution of mammals.

Keverne $(2001 \mathrm{a}, \mathrm{b})$ has pointed out that in the early mammals maternal behaviour was largely controlled by the neuroendocrine system. As mating and 
breeding was geared to seasonal fluctuations, behaviours were in the early mammals regulated by hormones and neural systems that 'translated' the environmental conditions into appropriate behaviour. However a shift occurred during the evolution of later mammals. In 'higher' animals like primates sexual behaviour and maternal behaviour have been 'emancipated' from the neuroendocrine mechanisms. In the case of the human species, the development of a larger neocortex enabled females according to Keverne to develop motivated behaviour to occur at will such that maternal affiliation can take place without pregnancy and parturition. The development of maternal behaviour associated with an enlarged neocortex evolved according to Keverne in social groups based on matrilineal inheritance. It led to the evolution of an 'executive brain' appropriate for volitional maternal behaviour (planning, caring, teaching, etc.). Since brain studies on chimeric mice (that are mixtures of normal cells and cells that contain a diploid set of either maternal or paternal genes) has shown that cells with paternal genes play a critical role in development of the hypothalamus, while cells with maternal genes are important for the development of the neocortex and the striatum (Allen et al. 1995; Keverne et al. 1996), Keverne distinguishes a paternal and maternal brain. He assumes that maternally expressed genes (from now on MEGs) contribute to the development of a maternal brain involved in executive functions, and that paternally expressed genes (PEGs) contribute to the development of subcortical brain structures.

Badcock and Crespi have used these ideas of Keverne for explaining autism and schizophrenia. In their kinship model they assume that the contribution of the father to the raising of a child is minimal compared to that of the mother: she is the major provider of care both during prenatal and early postnatal stages. Hence the father can only rely on his genes: they are the primary means for him to affect the behaviour of his child. Badcock and Crespi expect paternally-derived genes to promote 'selfish' behaviour at the expense of the mother and sibs. This explains according to them why PEGs contribute to the limbic system (this system includes in their view the hypothalamus) since this system modulates basic drives, appetites, and emotions. What they call 'mechanistic cognition' is, therefore, conceived as an extension of 'selfish' behaviour modulated by PEGs expressed in the limbic system. However, how 'mechanistic cognition' is understandable as an extension of 'selfish drives' is left unexplained. Since the mother is the major provider of care and therefore can exploit her role during nurturing, Badcock and Crespi expect that maternally derived genes have an interest in 'building a cortical brain capable of integrating mental activity in the greater interests of her whole family' (Badcock and Crespi 2006, p. 1011). Hence they assume that MEGs contribute to the development of 'mentalistic cognition' by promoting the development of the neocortex. The explanation they have developed for autism and schizophrenia is now easy to understand: they assume that there are several causes for an imbalance between the effects of PEGs and MEGs on brain development resulting in either an extreme paternal brain (lack of social, mentalistic cognition: autism) or an extreme maternal brain (exaggerated 'mentalistic cognition' leading to schizophrenia). 


\section{Evolution and the mental domain}

Badcock and Crespi contrast two parts of the brain: the neocortex, which is responsible for 'mentalistic cognition' and which enables children to develop a ToM, to make decisions, to formulate thoughts and believes, etc. And the subcortical parts which regulate and modulate drives, sensations and emotions, and are responsible for 'mechanistic cognition' (conceived as a cognitive extension of these drives, sensations, and emotions). They assume, presumably, that the cortex does different things than the subcortical parts. For instance: subcortical parts can regulate behaviour (like instincts and drives) through neuro-endocrine mechanisms, while cortical parts enable us to develop 'mentalistic cognition' through for instance synaptic plasticity involved in learning and memory consolidation. Although there are differences between the activities of neurons in subcortical and cortical parts of the brain, the problem arises whether these differences license us to distinguish 'mechanistic and mentalistic cognition'. For the transmission of action potentials or the release and re-uptake of neurotransmitters in the synapse (explicable in terms of neuro-physiological and biochemical models), do not tell us anything about 'mechanistic and mentalistic cognition'. How and why do Badcock and Crespi distinguish two modes of cognition? In the following I will only discuss Badcock and Crespi's ideas on the evolution of ToM.

Suppose that I see that another feels pain, is jealous, or is mourning, then I am according to Badcock and Crespi using a ToM for understanding these mental phenomena in others. Yet if scientists observe my brain, they will observe just neural activities or processes. What (scientific) evidence can be given that clarifies or proves that my brain 'produces' a ToM? To see why this is a problem, I will first recapitulate Williams' arguments for disregarding the mental domain in scientific discourse (Williams 1985). Since Badcock (2003) criticized Williams' 'anti-mentalism', the question arises whether the alternative model of Badcock and Crespi provides adequate solutions for the problems discussed by Williams.

Williams advanced the well-known argument that mentalism (based on Cartesian dualism) cannot be empirically tested, since there are no criteria of identity of the mind defined as an immaterial substance. We do not know how to identify the mind as an immaterial substance, how to measure this substance, etc. 'The power of positive thinking has never been measured in calories per second, nor a burden of grief in grams' (Williams 1985, p. 22). And since there are no criteria to identify the mind, it is senseless to say that the mind has causal powers and can, therefore, interfere with physical processes. Mental phenomena and physical phenomena, as Williams put it, lack a commonality. We would not know what kind of empirical evidence someone can provide if he argues for example, that the mind causes a voluntary movement (or that the brain 'produces' a ToM). For how can we determine that an immaterial substance causes this movement if we cannot identify this substance? Williams concluded that introducing mental concepts into the biological domain does not add anything to scientific explanations (efficient causes, i.e. the laws of physical sciences and natural selection). Hence he proposed to delete the mental realm from biological explanation. 
Williams also argued against those scientists who reasoned that the mind is selfevident on logical grounds. For that amounts to saying that the mind is demonstrated by introspection and to the thought that the mind of other animals is understandable indirectly by analogy. Williams concluded that:

'... the animal-mind problem is merely a special case of the other-mind problem that has troubled philosophy ever since it began. I feel intuitively that my daughter's horse has a mind. I am even more convinced that my daughter has. Neither conclusion is supported by reason or evidence'. (Ibid, p. 21)

At face value these arguments do not seem to affect Badcock and Crespi's model. First, Badcock and Crespi do not defend Cartesian dualism and do not suppose that the mind interferes with physiological processes. Secondly, they do not endorse the argument from analogy as a solution for the other-mind problem. Badcock and Crespi assume that the other-mind problem has been solved during the course of evolution: a ToM evolved that enables creatures to predict the 'mental states' of other organisms. The challenge for Badcock and Crespi is, then, to explain which selective forces operating on physical processes gave rise to 'mentalistic cognition' as a separate module (and, subsequently, how MEGs modulate the development of this form of cognition). What evidence (in terms of the laws of physical sciences and natural selection) for the evolution of 'mentalistic cognition' is at their disposal? Since a ToM is a component of social cognition, it is usually explained in terms of the evolution of cooperation. Hence models from game theory (like the iterated Prisoners dilemma game) have been mentioned as possible explanations for the evolution of ToM. I will distinguish two possibilities.

First, mathematical models developed to explain the evolution of direct reciprocity (direct reciprocity is captured in the principle: 'You scratch my back, and I'll scratch yours') demonstrate that cooperation evolves under certain conditions. However, since these models also apply to cooperative behaviour in 'lower' animals, they do not provide answers to the question as to why ToM evolved as a distinct form of 'mentalistic cognition' in just 'higher' mammals. Secondly, models explaining the evolution of indirect reciprocity have been mentioned as more promising for understanding the evolution of ToM (see for example Nowak and Sigmund 2005). These models demonstrate that cooperation evolves when, for example, rumour about the reputation of players is spread in a population. Suppose that $\mathrm{C}$ observes that $\mathrm{A}$ helps $\mathrm{B}$. If $\mathrm{C}$ informs others in the population on the reputation of $\mathrm{A}$ ('A is generous'), then this information may be used by others (called discriminators in the game) to engage cooperatively with A. Hence the model requires the spread of information (called gossip) about the reputation of players. Indirect reciprocity is captured in the principle: 'I won't scratch your back if you won't scratch their backs'. It is thought that language may have evolved in populations playing games by indirect reciprocity, for players must be able to explain and understand the information about a certain individual. If models on indirect reciprocity are used to explain the evolution of ToM, then ToM evolved only in a language-using creature and is, therefore, unique for the human species. But it is not an argument in favour of ToM. Although it clarifies why humans discuss information about someone's reputation, it does not say that we need a ToM 
for understanding the invisible 'mental states' of others. All it says is that we use behavioural evidence presented to us by others (C: 'yesterday I saw A helping B'). Consequently indirect reciprocity does not prove that we use a ToM to predict unobservable mental states, for $\mathrm{C}$ made an observation which belongs to the publicly demonstrable (of course, $\mathrm{C}$ can make mistakes or may lie about $\mathrm{A}$ ). Below I will return to the connections between behaviour and language.

The (current) models from game theory do not solve Williams' problem: they do not prove that a ToM evolved as a solution to the other-mind problem. This is presumably the reason why Badcock and Crespi opt for another possibility: the ideas of Keverne on the 'emancipation' of maternal behaviour in 'higher' mammals. But Keverne's remarks about the 'emancipation' of maternal behaviour are merely (re) descriptions of the differences between 'mechanistic' behaviour regulated by the neuroendocrine system and 'mentalistic' behaviour displayed at will (he did not develop an evolutionary explanation). Hence Keverne's ideas do not provide us with a criterion for identifying species that do and do not possess 'mentalistic cognition'. This diagnosis raises the question as to whether there are conceptual issues at stake that blur problems.

\section{Behavioural manifestations of the mind}

Just as Williams, Badcock and Crespi assume that the mind is essentially a private phenomenon. Williams stated that mental phenomena are not publicly demonstrable and thought that the other-mind problem cannot be solved. Badcock and Crespi assumed that the other-mind problem has been solved during the course of evolution, but did not develop an explanation. But Badcock, Crespi, and Williams did not mention an alternative solution originally developed by Aristotle: monism. According to this conception of the mind, the other-mind problem can, indeed, not be solved. But the reason why it cannot be solved is according to Aristotelians that there is no problem to be solved. The other-mind problem is according to Aristotelians a non-problem arising only within the confines of the incoherent, Cartesian (or crypto-Cartesian) framework (see Hacker 2007 and Smit 2010a, for a discussion of the differences between the (crypto) Cartesian and Aristotelian framework). If the alternative Aristotelian conception of the mind is taken as a starting point for investigations, then the other mindproblem does not arise for the simple reason that the minds of others are publicly observable. Moreover, within the Aristotelian framework other problems can be formulated that are far more interesting for prospective investigations. I will first briefly discuss why the mind is publicly observable and will then answer the question what the alternative conception of the mind teaches us about autism and schizophrenia.

In contrast to the Cartesian and crypto-Cartesian conception of the brain/mind, Aristotelians argue on logical grounds that the application of mental predicates to others is based on behaviour. We use behavioural manifestations of the mind as criteria for the application of these predicates, for 'mental phenomena' are expressed in behaviour. For instance: when we observe children or chimpanzees 


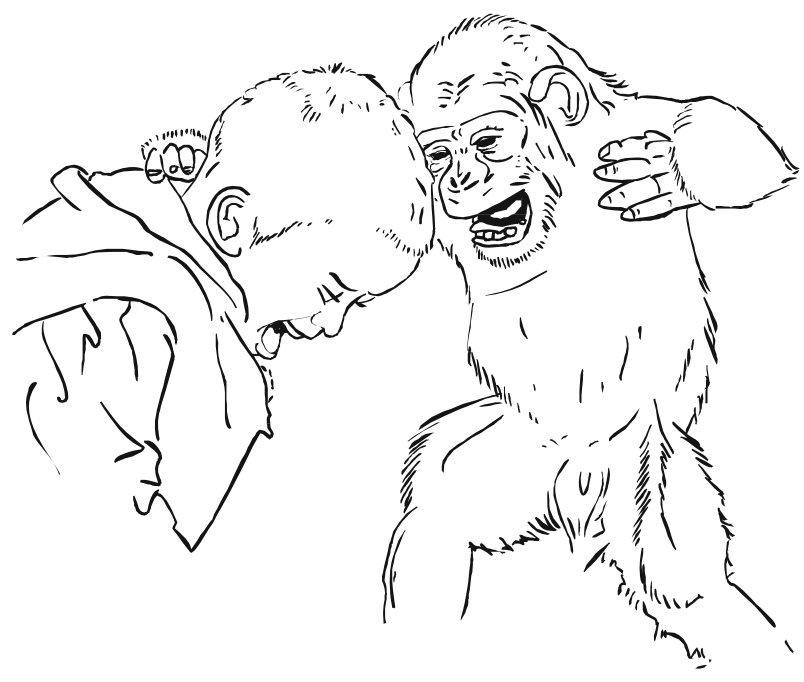

Fig. 1 Drawing of the facial expressions of a boy and a chimpanzee during play (from Van Hooff 1972)

playing (see Fig. 1), then we do not first observe the contractions of the facial muscles and subsequently develop the prediction, derived from a ToM, what the invisible 'mind states' of the boy and the chimpanzee are. We see their facial expressions and, hence, observe the manifestations of their minds. If we want to explain to others what we perceive, we can mimic the facial expressions and can explain the context in which these expressions are displayed, i.e. play. Hence the criteria for applying mental predicates are behavioural, for 'similar expression' takes faces together in a quite different way from 'similar anatomy' (Wittgenstein 1980, par. 1068).

Darwin (1965[1872]) already noted that the expression of emotions is publicly demonstrable. They can be identified by observers, we can point to a certain facial expression if we want to explain an emotional expression, and we can make a photograph or a drawing of an expression which can be used as samples (or paradigms) for identifying similar expressions of emotions in others. Ethologists use these samples, further classified in an ethogram, when they are investigating animal behaviour. Ekman used pictures of emotional expression in order to study whether primary emotions are universally recognized (Ekman et al. 1969; Ekman and Friesen 1971). Of course, the use of samples in the case of expressions of emotions differs from the use of samples of, for example, chemical substances or anatomical structures. Except from instinctive behavioural expressions in infants, the meaning of expressions becomes in older children circumstance-dependent. Older children are able to smile at will and the circumstances indicate whether a given smile was an expression of joy or timidity. A picture does not capture these different meanings.

Facial expressions are in older children no longer the sole criteria for identifying someone's emotions or moods. Hence the emotional life of older children will be studied with other methods than through observing the instinctive expressions (or bodily reactions) of children and animals (Kenny 1963, Chap. 2). Hence the 
problem for Aristotelian monism is to describe how behaviours that can be displayed at will grow out of instinctive behaviour.

\section{Instinct as precursor of the mind}

It has been noted by evolutionary biologists like Weismann, and ethologists like Lorenz and Tinbergen, that newborn animals display behaviour instinctively, i.e. unhesitatingly and spontaneously. For example Weismann described instinctive behaviour as follows: 'All around we can see that animals know how to use their parts or organs in a purposeful manner: the duckling swims at once upon the water; the chicken which has just been hatched from the egg pecks at the seeds lying on the ground; (...) and the predatory wasp requires no instruction to recognize her victim, (...) she knows how to attack it, to paralyse it by stings, and then hesitates not a moment as to what she has to do next (...)' (Weismann 1983[1904], vol. 1, p. 141). According to Weismann, these instincts guide animals towards ends without having any consciousness of these ends. However, when we say that animals 'know' how to use the limbs of their body, we do not mean that instincts inform them how to do this. Weismann (Ibid, p. 146) quoted Lloyd Morgan who wrote in Habit and instinct about the pecking behaviour of chicks: 'It does not pick at the seeds because instinct says to it that this is something to be picked up and tested, but because it cannot do anything else'. Hence instinctive behaviour is according to Weismann displayed without reasoning. If instincts were inherited habits (and amenable to reason), as Lamarck and others had argued, than there should be evidence of the possession of 'that degree of intelligence which would have induced the variation in the previous habit, that is, in manner of movement' (Ibid, p. 155). However, since instinctive behaviours are displayed stereotypically and without hesitation, this showed to Weismann that they are at first performed without reasoning (cf. Smit 2010b). In 'higher' animals instinctive behaviour can according to him be modified or inhibited by intelligence. In humans instinctual behaviour transforms into intentional behaviour. Weismann discussed breastfeeding as an example. The suckling of a baby is at first an instinct: the child seeks about with its mouth. Yet if the sucking 'is continued into the second year of life, as not infrequently happens in the southern countries of Europe', it is an example of primitive intentional behaviour since the 'child knows exactly why it wants the breast' (Weismann 1983[1904], vol. 1, p. 143). The child can express its bodily sensations verbally and can ask for the breast if it is hungry. It no longer seeks the breast instinctively but acts out of a bodily desire, i.e. hunger or thirst. And if it acts out of a desire, the child learns to refrain temporarily from satisfying the desire.

Since instinctive behaviours are at first displayed without preceding learning processes, it is assumed that they are largely innate and, hence, can partly be explained in terms of the laws of the physical sciences and natural selection during the early stages of development. Instinctive behaviours can be described as a concatenated series of movements. They resemble reflexes since instinctive behaviour can, just as a reflex, be triggered by a single stimulus. For instance: a baby seeks about with its mouth and this instinctive behaviour is triggered by a 
(internal or external) stimulus. The concatenated series of movements end with, what ethologists like to call, a consummatory act. The baby starts to suckle as soon as it has found a nipple. So in contrast to the (crypto) Cartesian conception, the Aristotelian conception of behaviour emphasizes the goal-directness of adaptive, instinctive behaviours as the beginning for the development of later 'mental behaviour'. The advantage of the Aristotelian conception of the mind is that it explains the rise of complex goal-directed behaviour and intentional behaviour as extensions of instinctual behaviour. Aristotelians do not assume a distinct, invisible mental domain. I will elaborate the development of mental phenomena out of instincts and first will use sensations and emotions as an illustration.

The instinctive emotional and sensational behaviours displayed by children have a (species-) characteristic facial expressions, bodily postures, and vocal expressions. For instance: if an infant is in comfort or discomfort, he or she will display a characteristic facial expression (like smiling) or will start to cry. If one-year-old children are taught a language or pick up words and sentences from adults, they add linguistic expressions to these natural behaviours. In stead of displaying a facial expression they can say: 'I feel pain' or 'I feel anxious'. In the case of the sensation pain they learn to add to their natural pain-locative behaviour (of clutching the part that hurts) verbal indications of pain location (e.g. 'my head hurts', 'I have hurt my finger'); in the case emotions children learn what appropriate objects of the relevant emotions are (for example they learn to answer the question: 'What are you frightened of?'). Like the original behavioural expressions, these linguistic utterances are expressions of emotions and sensations themselves. However, these learnt extensions of natural behaviour create new possibilities for communication about emotions. If a child learns to use a language, it will be able to answer the question why it is angry and what the object of its anger is. Whether crying is an expression of discomfort, pain or fear is therefore, in certain circumstances, no longer confusing for parents: if a child has pain it can say where the pain is located, and if it is anxious, it will refer to an object of fear ('a scary dog'). Hence it is able to specify the location of pain or give reasons for its emotion, for it can explain that a dog bites, and, hence, why it wants to run away. Of course, if the dog is a very friendly one, an adult can explain to the child why the fear is unwarranted.

The point to notice is that these learnt extensions of instinctive behaviours are not based on (introspective) observations which are privately accessible only to the owner of the mind (and are, as a corollary, only understandable by observers if they possess a ToM). For the learnt extensions of instinctive behaviours are not based on knowledge. They are essentially groundless (they are not grounded in empirical observation or in reasoning), for we cannot first identify an emotion or sensation in our brain or mind. Hence first person present tense utterances like 'I am anxious' cannot refer to an object visible to an 'inner eye': introspection is not an inner observation. When someone is saying: 'I feel fear' he is not feeling or observing his fear somewhere in his mind or brain (as someone may feel with his fingers that the penny in his pocket is rough or smooth). The avowal is a verbal expression of an emotion just as the original instinctual, facial expression. It is, for that reason, called a new form of emotional behaviour. Of course, it is possible that someone is not angry or anxious when he says that he is. But then he is insincere: he is lying and, 
perhaps, trying to mislead others in a certain situation. But this is only possible after someone has learnt to pretend to be angry or jealous and presupposes the ability that creatures have learnt to display these behaviours at will.

\section{Intentions, beliefs, and schizophrenia}

First-person present tense utterances are groundless, for it makes no sense to ask for, or to give evidence for these utterances. This not only holds for sensations and emotions, but also for beliefs and intentions. Someone's belief tells us something about what is credible according to him; his intentions about his future behaviour. If I say that I have the intention to go to Amsterdam next week, I am telling something about what I will do in the future. I have knowledge of the future since I know what I will do because I have formed an intention. Yet saying that 'I know what I intend to do' is not a cognitive assertion based on (empirical) evidence (of course, expressing the intention that I will take a train presupposes knowledge about train schedules). Expressing or declaring an intention and adding 'I know ...' is only a way of revealing that one has made up one's mind, or of an expression of a concession, or of that one has finally made a difficult decision. Ignorance, doubt, and lack of (empirical) knowledge are, therefore, logically excluded. For example: when someone says 'I do not know what I intend to do', then he does not express ignorance, but indecision. Similarly, when someone says 'I believe that p', this is a confession based on what he thinks that may be the case, i.e. p. Although information about $\mathrm{p}$ is relevant for this utterance, he is expressing his belief, i.e. he makes clear what he thinks is credible and is, perhaps, important for him.

Since intentions and beliefs, just like sensations and emotions, are expressed in nonverbal and verbal behaviour, we, as observers, can directly observe what someone is up to. When someone is crying or laughing we do not first observe mechanical movements and, after we have learnt to use a ToM, make predictions about an unobservable inner life. Likewise we do not infer with the help of a theory of mind what someone's beliefs or intentions are when he says that he beliefs p or plans to take a train next week. Since we express our beliefs and intentions, it is mistaken to suggest (as Williams did) that our inner life is not publicly observable. The problem of the hidden inner life and, hence, the other mind problem, arises only within the incoherent (crypto) Cartesian framework. In the following I will argue that the symptoms of schizophrenia are likewise publicly observable.

Save in cases of lying or self-deception, one does not believe $p$ and simultaneously assert that is not the case that $\mathrm{p}$. For a rational creature does not believe something that he knows to be false. To recognize that something is incredible is a reason for ceasing to believe it. Suppose I am told by sincere people that a certain belief or thought is false, then I will stop believing it. But suppose that I cannot stop believing or thinking it. In that case I cannot say that 'I still believe that $\mathrm{p}$ for good reasons', but will perhaps say that 'I cannot help thinking, believing, imaging that p'. In the worst case I am haunted by a thought and in the grip of a delusion or fantasy. For example I may haunted by the thought that someone is following me. If so, then the haunting thought may be a symptom of paranoia. This 
is one of the behavioural criteria for saying that someone may suffer schizophrenia. Another criterion is that someone hallucinates (hears voices, etc.). Hence we can describe the so-called 'mentalistic disorder' schizophrenia in terms of behavioural manifestations and do not need to make an incoherent conceptual distinction between observable movements and an invisible mind.

Disrupted formation of intentions may also be a symptom of psychopathology. Suppose that I form the intention: 'I will go to Amsterdam tomorrow'. If someone replies with 'No, you will not; there are no trains tomorrow', then I will change my intentions. But suppose someone utters this intention but often, without changes in train schedules, does not take a train. If we observe this person, we will ask him the next time when he utters this intention: 'Are you sure?' If he replies with: 'I hope so, unless something happens to change my mind', we will be puzzled by his answer although we now understand why his expressions of intentions are unreliable for predicting his future behaviour. It raises the question why this person cannot develop firm intentions. Does he have a weak will or is he confused about his wants and plans? Now take the opposite case: suppose that someone forms an intention, but it is obvious that this intention would be a mistake for him (there are good reasons for him not to do what he intends to do). Yet suppose that he insists on doing what he has decided to do. Since his plans are impervious to reason we will conclude that he is in the grip of a compulsion. He is not, as Hampshire (1965) has explained at length, a free person, for he cannot respond to reason (see also Hacker 2005). Obsessive compulsive behaviour is, for example, characteristic of girls with anorexia nervosa who display obsessive-compulsive slimming behaviour. The insistence on sameness in the case of autism reminds one of it too.

\section{Emotions, caring, and autism}

The logic of emotions is to a certain extent the opposite of the logic of intentions, since emotions are traditionally referred to as passions. They are not actions or things one does or chooses, but things one feels. One cannot order a person to feel an emotion, as one can order someone to perform an action. Likewise one cannot decide to love or hate, to be angry or to feel jealous. One may be in the grip of or full of an emotion. Hence when I am saddled with a passion, I am not the author of my emotion, for I do not decide after deliberation or decision to feel an emotion (and am therefore angry or anxious). By contrast: I am always the author or designer of my intentions, for I form my intentions. These patent differences between emotions and intentions have been used to argue that emotions belong to 'mechanistic cognition' and are the opposite of 'mentalistic cognition'. And since emotions appear to belong to the passive, it has been argued emotions are the carrots and sticks of genes (Haig 2006). As a corollary, a distinction is made between our 'mechanical emotional life' and 'mentalistic cognition'. Hence it is postulated that PEGs may affect child behaviour through their emotional life. Autism is then a disorder caused by a disturbance in the development of 'mentalistic mode of cognition'. Hence one of the problems left unexplained within this conceptual framework is how this cognitive development relates to our passive emotional life 
'designed' by genes. On the one hand, emotions are described as the carrots and sticks of genes and are partly constitutive for the development of "mechanistic cognition'. On the other hand ToM is a component of the 'mentalistic mode of cognition'. I will discuss an alternative view.

Children express emotions in their behaviour. Later they learn what the appropriate objects of emotions are. They learn which dangerous animals or situations are objects of fear, they learn that worthy achievements are objects of pride, and learn that offensive remarks are objects of anger. Hence they learn to use words to express their feelings towards objects and learn to use these words in their descriptions of the emotions expressed by others. This does not mean that emotional responses can no longer be triggered by a single stimulus. This was already noted by Darwin. While visiting the Zoological Gardens, Darwin noticed that he was unable to control his response to the attack of a snake: 'I put my face close to the thick glass-plate in front of a puff-adder in the Zoological Gardens, with the firm determination of not starting back if the snake struck at me; but, as soon as the blow was struck, my resolution went for nothing, and I jumped a yard or two backwards with astonishing rapidity. My will and reason were powerless against the imagination of a danger which had never been experienced' (Darwin 1965[1872], p. 38). The results of Darwin's experiment are explicable in terms of the wellknown model of LeDoux (1998): there are two pathways in the brain, i.e. a cortical and subcortical pathway. The presence of the subcortical pathway makes clear why Darwin reacted mechanically when confronted with the fearful object. His experiment shows that, although our emotional life is an extension of innate emotional responsive dispositions and tendencies, the bodily responses and facial expressions are not fully replaced by a 'cognitive emotional life'. But with maturation, emotional responses come to a much greater degree under the control of reason and reflections. For that reason one can discover later in life that emotional responses, mediated by the subcortical pathway, are unwarranted and, hence, disappear. In these cases we refer to the object in order to explain why the emotional response was unwarranted. Suppose that a child is lying in bed and hears the noise of a stair. The noise may frighten the child since it associates the noise with a burglar. Yet the child is afraid of a burglar (the object on an emotion) and if the child notices that the noise is produced by a cat, the emotion will cease since the fear is no longer warranted.

When emotions get appropriate objects children become able to act out of an emotion (emotions become a motive for acting): they develop so-called emotional attitudes. These emotional attitudes are, in contrast to innate responses, thoughtdependent. Hence, humans can change their attitudes in response to changes in the relevant properties of the object of their emotion. I am no longer proud if my son has cheated during the examinations, I am no longer jealous if someone convincingly explains to me that my belief that my girlfriend is dating another is wrong. Hence although emotions initially belong to the passive (they are not, like intentions, formed at will), older children are able to control their emotions and act out of emotions.

An interesting topic is the development of caring. Caring is not a uniquely human attribute, yet the caring behaviour of language-using creatures is richer than that of 
other animals. This is reflected in the concerns of humans. A boy may be worried about the well-being of his girlfriend now but may also be worried about happens to her next Friday (when she has to visit a doctor) and send her once and again a SMS to support her. Note that his actions are goal-directed:: if he acts out of love or care, then he can specify the (future) objectives of his actions. However, since cognition is an essential part of the emotional life of the boy, his emotional life may change. When the girlfriend ceases to matter to him, he will cease to feel anything about her. His emotions disappear and he will care less about her. This example shows that, through manifesting his emotions, the boy showed what is (no longer) important for him. The manner in which the object of his emotion (his girlfriend) matters to him reveals why. Hence the thoughts and beliefs of emotional attitudes are important for understanding someone's emotional life.

Patients with lesions in their orbitofrontal cortex do not act out of care. They appear to be indifferent as they do not feel emotions and do not pursue goals related to caring about others. In this respect they behave like autistic persons who, probably due to an early neuro-developmental disturbance, do not develop an emotional life in which caring is a motive for entering emotional interactions. If the development of the ability to apply mental predicated to others is studied in children with autism when they are older than four, then it is noticed that they have problems solving false belief-tasks. Yet this is the outcome of a developmental trajectory. There are many other symptoms discernable during earlier stages (lack of pretend play, problems with recognizing emotions, etc.). Hence it is possible that the socalled cognitive disorder is rooted in a disturbed affective development.

Whatever the early precursors of autism are, the analysis given suggests that the idea that autism is caused by a disturbed development of ToM is mistaken. For there is no such thing as a theory of mind and, consequently, imprinted genes did not evolve for their contribution to the development of a theory of mind. Moreover, a strong focus on a cognitive developmental trajectory culminating in ToM disregards the possible contribution of a disturbed affective developmental trajectory in the aetiology of autism. This is an oversight since there is evidence that imprinted genes contribute to this trajectory.

\section{Genomic imprinting and the development of social behaviour}

If imprinted genes, for conceptual reasons, cannot contribute to the development of 'mentalistic cognition' yet affect the development of social cognition and communicative behaviour, what could an alternative hypothesis be?

Weismann discussed the transition from (instinctive) sucking to intentional behaviour ('asking for the breast'). There is evidence showing that PEGs affect the instinctive suckling behaviour of babies (Plagge et al. 2004). Given these 'selfish' effects of PEGs, kinship theory predicts the evolution of maternally-expressed genes that counteract these effects of PEGs and contribute to mechanisms and behaviours that enhance inclusive fitness. One can hypothesize that MEGs benefit from an earlier transition to intentional behaviour, since an earlier transition increases the chance that the mother can get pregnant and makes children less demanding (Smit 
2009). One can also hypothesize that maternally-derived genes benefit from the development of skills necessary for collaborative actions, since these actions are needed for a just distribution of food among siblings (under parental control). By contrast: paternally-derived genes benefit from behaviours that will help an individual to compete with siblings. I will briefly discuss the possibility that imprinted genes affect the development of crying, reactive crying and the development of collaborative action.

The affective development of children begins with simple emotional expressions like crying and smiling. It is thought these instinctive behaviours of a newborn are adaptive behaviours since they evoke maternal care (for a critical discussion, see Blumberg and Sokoloff 2001). Yet newborn babies also cry when they hear another infant cry. Reactive crying was found in 2- and 3-day-old babies by Simner (1971) and he noted that it was not the loudness of the cry that evoked the response. This finding has been replicated by Sagi and Hoffman (1976) in 1-day-olds. They showed that the reactive cry is indistinguishable from the spontaneous cry of an infant who is in actual discomfort. Martin and Clark (1982) later demonstrated that infants do not react as much to the sound of their own cry. This finding has been replicated by Dondi et al. (1999). One can argue that this innate response to the cry of another of the same species is an adaptive response since it increases the chance that the child receives maternal care. In a simple model, reactive crying increases the chance that the child will receive maternal care at the expense of another. Kinship theory, i.e. Trivers' ideas on parent-offspring conflicts (Trivers 1974), predicts that this response to another's cry may have been subject to a genetic conflict. If imprinted genes are involved, then one can hypothesize that PEGs promote reactive crying.

Six month-old infants do no longer respond 'mechanically' to another's cry: they appear to respond to the distress of another only after the other displayed several instances of distress. Moreover the cry displayed by a 6-month-old is different from a newborn's cry: the infant looks sad and puckers his lip before starting to cry, just as infants do when they are in actual stress. The response of a one year-old is similar to the response of a 6-month-old but their cry is now accompanied by whimpering and silently watching or staring. As soon as children are able to crawl and later become self-moving, walking creatures, they actively seek comfort in their mother's lap (cf. Hoffman 2000).

Pro-social behaviours (instrumental helping, concern for others, etc.) replace reactive crying after about 12-14 months and increase during the second and third year, although the base rates are low (Svetlova et al. 2009). Since these behaviours are not instinctive responses but examples of primitive intentional actions, there are various forms of helping (first patting and touching, and later kissing, hugging, giving physical assistance, getting someone else to help, and giving advice). However, the fact that pro-social behaviours replace reactive crying does not mean that children do no longer behave 'selfish'. For example two- and three-year olds sometimes help when they witness a distressed other, but do not help if they cause the distress (cf. Zahn-Waxler et al. 1992). Hence it is unlikely that MEGs evolved that cause (the development of) certain pro-social behaviours. How then can MEGs contribute to the development of collaborative actions among siblings and the mother? One possibility is that MEGs contribute to (learning) behaviours necessary 
for collaborative behaviours, such as pointing and understanding other's goaldirected behaviour, for these behaviours help to coordinate actions in a family (Smit 2009). It is interesting to note that the development of behaviours necessary for collaborative action begins around the age when children develop milk teeth and breastfeeding is extended with supplementary food. Whether these behaviours and skills are also a prerequisite for the development of empathic behaviour and cause, in the case of disturbed gene expression, autism, is a topic for future studies.

\section{Conclusion}

I have used in this paper the traditional conceptual distinction between the (crypto) Cartesian framework (used by Badcock and Crespi) and the Aristotelian framework (used by, among others, Darwin and Weismann) to explain how two conceptions of the mind result in different hypotheses about the possible effects of imprinted genes on brain and behavioural development. Badcock and Crespi have argued that there are two modes of cognition: mechanistic and mentalistic cognition. They have argued that schizophrenia (and the Prader-Willi syndrome) is explicable as an extreme of the mentalistic mode of cognition, and autism (and the Angelman syndrome) as an extreme of the mechanistic mode of cognition. There are several causes of these disorders, but Badcock and Crespi have suggested that the pathogenesis is similar in most cases since the different causes all affect the same brain pathways or structures in the brain. These pathways or structures are, according to Badcock and Crespi, regulated or modulated by imprinted genes. There is, however, no evidence that imprinted genes are selected because of their alleged (inclusive) fitness-effects on the development of mentalistic and mechanistic cognition. I have argued that it is doubtful whether we can investigate their model since it suffers conceptual incoherence.

According to the alternative Aristotelian conception of the mind, imprinted genes may affect the development instinctive behaviours and verbal and nonverbal behaviours growing out of instincts as the result of maturation and learning. Weismann discussed the transition from (instinctive) sucking to acting out of a sensation ('asking for the breast') as an example. There is evidence that imprinted genes are involved in suckling and the transition to intentional behaviour. Hence it is also possible that imprinted genes affect the transition from (reactive) crying to primitive, intentional behaviours, since these behaviours have different effects on the inclusive fitness of paternally and maternally derived genes. One can hypothesize that PEGs contribute to more 'selfish' behaviours like crying and reactive crying, while MEGs modulate the development of behaviours and skills necessary for joint action in the (extended) family. This hypothesis explains why PEGs are involved in brain structures and processes in the hypothalamus regulating instinctive behaviours, while MEGs modulate brain processes such as long term potentiation involved in learning skills.

I have argued that the (crypto-Cartesian) model advanced by Badcock and Crespi is mistaken and have advanced an alternative hypothesis. Although it is unknown whether this hypothesis holds, it is known that that the lack of expression of 
imprinted genes in children with Prader-Willi syndrome (lacking the effects of PEGs) and Angelman syndrome (lacking the effects of MEGs) causes disruptions in crying and in the development of communicative behaviour. Hence a study of early development in children with Prader-Willi and Angelman syndrome will provide some answers.

Acknowledgement I am grateful to Peter Hacker for discussions and his comments on an earlier draft of this paper. I should also like to thank two reviewers for their comments.

Open Access This article is distributed under the terms of the Creative Commons Attribution Noncommercial License which permits any noncommercial use, distribution, and reproduction in any medium, provided the original author(s) and source are credited.

\section{References}

Allen ND, Logan K, Lally G, Drage DJ, Norris ML, Keverne EB (1995) Distribution of parthenogenetic cells in the mouse brain and their influence on brain development and behaviour. Proc Natl Acad Sci USA 92:10782-10786

Badcock G (2003) Mentalism and mechanism: the twin modes of human cognition. In: Crawford C, Salmon C (eds) Human nature and social values: implications of evolutionary psychology for public policy. Lawrence Erlbaum Associated, Mahwah, pp 99-116

Badcock G, Crespi B (2006) Imbalanced genomic imprinting in brain development: an evolutionary basis for the aetiology of autism. J Evol Biol 19:1007-1032

Baron-Cohen S (1995) Mindblindness: an essay of autism and theory of mind. MIT Press, Cambridge, Mass

Blumberg MS, Sokoloff G (2001) Do infant rats cry? Psychol Rev 108:83-95

Crespi B, Badcock C (2008) Psychosis and autism as diametrical disorders of the social brain. Behav Brain Sci 31:241-261

Darwin C (1965[1972]) The expression of the emotions in man and animals. University of Chicago Press, Chicago

Dondi M, Simion F, Caltran G (1999) Can newborns discriminate between their own cry and the cry of another newborn infant? Dev Psychol 35:418-426

Ekman P, Friesen WV (1971) Constants across cultures in the face and emotions. J Pers Soc Psychol 17:124-129

Ekman P, Sorenson ER, Friesen WV (1969) Pan-cultural elements in facial displays in emotion. Science 164:86-88

Grandin T, Johnson C (2005) Animals in translation: using the mysteries of autism to decode animal behaviour. Bloomsbury, London

Hacker PMS (2005) Thought and action: a tribute to Stuart Hampshire. Philosophy 80:175-197

Hacker PMS (2007) Human nature; the categorial framework. Basil Blackwell, Oxford

Haig D (2006) Intrapersonal conflict. In: Jones M, Fabian AC (eds) Conflict. Cambridge University Press, Cambridge, pp 8-22

Hampshire S (1965) Freedom of the individual. Chatto \& Windus, London

Hoffman ML (2000) Empathy and moral development. Cambridge University Press, Cambridge

Kenny A (1963) Action, emotion, and the will. Routledge, Kegan \& Paul, London

Keverne EB (2001a) Genomic imprinting, maternal care and brain evolution. Horm Behav 40:146-155

Keverne EB (2001b) Genomic imprinting and the maternal brain. In: Russell JA et al. (eds) Progress in brain research, vol 133. pp 279-285

Keverne EB, Fundele R, Narasimha M, Barton SC, Surani MA (1996) Genomic imprinting and the differential roles of parental genomes in brain development. Dev Brain Res 92:91-100

LeDoux J (1998) The emotional brain. Touchstone, New York. Reprint of the 1996 edition

Martin GB, Clark RD III (1982) Distress crying in neonates: species and peer specificity. Dev Psychol $18: 3-9$ 
Nowak MA, Sigmund K (2005) Evolution of indirect reciprocity. Nature 437:1291-1298

Plagge A, Gordon E, Dean W, Boiani R, Cinti S, Peters J, Kelsey G (2004) The imprinted signaling protein $\mathrm{XL} \alpha \mathrm{s}$ is required for postnatal adaptation to feeding. Nat Genet 36:818-826

Premack D, Woodruff G (1978) Does the chimpanzee have a theory of mind? Behav Brain Sci 1:515-526

Sagi A, Hoffman ML (1976) Empathic distress in the newborn. Dev Psychol 12:175-176

Simner ML (1971) Newborn's response to the cry of another infant. Dev Psychol 5:136-150

Smit H (2009) Genomic imprinting and communicative behaviour; Prader-Willi and Angelman syndrome. Neth J Psychol 65:78-88

Smit H (2010a) Conflicts in our mind. Theory Psychol (in press)

Smit H (2010b) Weismann, Wittgenstein and the homunculus fallacy. Stud Hist Philos Biol Biomed Sci (in press)

Svetlova M, Nichols S, Brownell CA (2009) Toddlers' prosocial behaviour: From instrumental to empathic to altruistic helping. Child Dev (in press)

Trivers RL (1974) Parent-offspring conflict. Am Zool 14:249-264

Van Hooff JARAM (1972) A comparative approach to the phylogeny of laughter and smiling. In: Hinde R (ed) Nonverbal communication. Cambridge University Press, Cambridge, pp 209-241

Weismann A (1983 [1904]) The theory of evolution, vol. 1, translated by J.A. Thomson and M.R. Thomson. AMS Press, New York

Wilkinson LS, Davies W, Isles AR (2007) Genomic imprinting effects of brain development and function. Nat Rev Neurosci 8:832-843

Williams GC (1985) A defense of reductionism in evolutionary biology. In: Dawkins R, Ridley M (eds) Oxford surveys in evolutionary biology. Oxford University Press, Oxford, pp 1-27

Williams GC (1992) Natural selection. Domains, levels, and challenges. Oxford University Press, Oxford

Wittgenstein L (1980) Remarks on the philosophy of psychology, vol. 1. In: Anscombe GEM, von Wright GH (eds) tr. Anscombe GEM, Basil Blackwell, Oxford

Zahn-Waxler C, Radke-Yarrow M, Wagner E (1992) Development of concern for others. Dev Psychol 28:126-136 